associated with drugs of the second category such as methyl dopa. ${ }^{10}$

Should we accept, then, that in general drugs will cause the disease only in patients who are genetically predisposed, and that the change in environment caused by the drug precipitates the full-blown syndrome? Attempts to reproduce it by prolonged administration of drugs to animals have failed, though some serological abnormalities can be shown. ${ }^{11}$ Further evaluation of the drug-induced lupus syndrome must largely depend on careful documentation of clinical cases in man and an awareness by clinicians that many drugs, chemically unrelated, can produce it.

\section{Violent Crime and the E.E.G.}

In 1935 E. D. Adrian and B. H. C. Matthews ${ }^{1}$ confirmed H. Berger's earlier work ${ }^{2}$ and showed the rhythmic electrical alpha waves in the electro-encephalogram, and it was not long afterwards that attention was directed towards the forensic field. F. A. Gibbs and his colleagues ${ }^{3}$ found abnormal E.E.G.s in 34 of 100 unselected criminals, and D. Silverman ${ }^{5}$ found a slightly smaller proportion in the general prison population. In the following year he reported much higher indices in selected samples: $75 \%$ in psychopaths and $45 \%$ in psychotics.

D. Stafford-Clark and F. H. Taylor ${ }^{6}$ introduced a useful classification of apparent motivation (incidental and in selfdefence, clear motivation, motiveless, sexual, insane) and this was taken up later by D. Hill and D. A. Pond, ${ }^{7}$ and J. N. Walton. ${ }^{8}$ There is an overwhelming preponderance of abnormal E.E.G.s in those murderers who are either insane or apparently motiveless; those with a clear motivation have about the same rate of E.E.G. abnormality as in the neurotic population or the prison population. Hill and Pond were impressed with the high proportion of definite epileptics (18 in their sample of 105 murderers); 38 had abnormal personalities, 37 a family history of mental disorder, and just over half showed abnormal E.E.G.s. Z. A. Sayed and his colleagues, ${ }^{9}$ using a sample of 32 murderers in a Scottish special hospital, found that $65 \%$ had abnormal E.E.G.s as compared with $15 \%$ in a control group of nurses and doctors; their figure of $65 \%$ was further divided into the psychotics $(78 \%$ ) and the psychopaths $(50 \%)$, and again the severity of the E.E.G. abnormality was related to the degree of psychiatric disturbance. It was principally Hill and D. Watterson ${ }^{1011}$ who first established clearly the strong correlation between aggressiveness of behaviour and E.E.G. abnormality; aggressive psychopaths, with their characteristics of "violent temper, overt aggressiveness or a recurrent tendency to suicide," showed $65 \%$ of E.E.G. abnormality, whereas the inadequate psychopath $(32 \%)$ was on much the same level as psychoneurotics, addicts, and sex-perverts.

Now an elegant paper by Denis Williams ${ }^{12}$ takes the story a little further. Starting with 333 violent criminals held in custody, he distinguished those who showed habitual violence from those who had perpetrated a single incidence of major violence; the two groups had $65 \%$ and $24 \%$ of E.E.G. abnormality respectively. These habitually violent criminals were not quite what most of us are accustomed to call aggressive psychopaths, most of whom continue to offend but often in a not very aggressive manner ${ }^{14}$-Williams's habitual aggressives are a very highly selected and dangerous group.
It is disconcerting that in this behaviourally very abnormal group no less than one-third have no E.E.G. abnormality. Williams's next move was to extract from both his groups all those cases in which there might on clinical grounds be a possibility of organic brain damage (those who had suffered a major head-injury, the epileptic, and the mentally retarded). This manoeuvre only accentuated the finding; when the offenders with possible structural lesions were excluded there was five times instead of three times the incidence of E.E.G. abnormality in the habitual as compared with the single violent offenders, who were then on a level with the general population. Williams concluded that in offenders who had done a single act of major violence we must look for the cause in the life situation, whereas in the habitually aggressive the kind of person, and more particularly the cerebral physiology, seems important. The nature of the E.E.G. abnormalities suggests to him that "the prime disorder of function . . . is in the diencephalic and mesencephalic components of the reticular activating or 'limbic' mechanisms, which have their densest projections to the anterior temporal and frontal cortex" rather than in the neocortex itself.

How does this help the forensic psychiatrist? Not as much as might be supposed. In practice the conclusions drawn by doctors, and the sentences passed by courts, are already to a considerable extent in conformity with these findings. Hill and Pond 7 showed in 1952 that even in those "hanging" days the motiveless murderer was recognized and treated relatively leniently: "Of 18 cases only 2 were executed. In 5 cases the prosecution reduced the charges during the trial to manslaughter. In 4 cases the prisoners were reprieved after being condemned to death . . . Society is very unwilling to hang such persons." Similarly with the fortunately uncommon cases of persistent serious violence there is usually no difficulty in finding the defendant diminished in responsibility and suffering from psychopathic disorder, whatever the E.E.G. findings. Abnormal E.E.G.s usually no more than confirm the clinical findings and they are of little value where they are most wanted-in the difficult borderline cases. Two factors, the occasional unexpected finding and the heavy responsibility in reporting to a court of law, will ensure that the E.E.G. will continue to be used even though (like other special investigations such as the chromosome karyotype) its principal value will be in the research field. Such a view was well stated by W. B. Matthews ${ }^{14}$ who, in referring to the characteristic temporal theta foci of psychopaths, wrote "The reasoning has somehow become inverted, and it is now often believed that the discovery of such foci in some way strengthens the diagnosis. A little thought will show that the personality will remain either psychopathic or normal whatever the results of the E.E.G., and that temporal theta foci are compatible with either."

1 Adrian, E. D., and Matthews, B. H. C., Brain, 1934, 57, 355.

Berger, H., Archiv für Psychiatrie und Nervenkrankheiten, vereinigt mi Zeitschrift für die gesamte Neurologie und Psychiatrie, 1929, 87, 527.

Gibbs, F. A., Bloomberg, W., and Bagchi, B. K., Transactions of the American Neurological Association, 1942, 68, 87.

- Silverman, D., Archives of Neurology and Psychiatry, 1943, 50, 18.

5 Silverman, D., Archives of Neurology and Psychiatry, 1944, 52, 38.

- Stafford-Clark, D., and Taylor, F. H., fournal of Neurology Neurosurgery and Psychiatry, 1949, 12, 325.

Hill, D., and Pond, D. A., Fournal of Mental Science, 1952, 98, 23.

Walton, J. N., Medico-Legal fournal, 1963, 31, 15.

Sayed, Z. A., Lewis, S. A., and Brittain, R. P., British fournal of Psychiatry, 1969, 115, 1115.

10 Hill, D., and Watterson, D., fournal of Neurology and Psychiatry, 1942, $5,47$.

11 Hill, D., Proceedings of the Royal Society of Medicine, 1944, 37, 317.

12 Williams, D., Brain, 1969, 92, 503.

Gibbens, T. C. N., Pond, D. A., and Stafford-Clark, D., fournal of Mental Science, 1959, 105, 108

14 Matthews, W. B., Lancet, 1964, 2, 577 